\title{
Design of an Antenna System in Wireless Communication Applications (2.45GHz ISM Band) by Applying FDSC Model
}

\author{
Settapong Malisuwan, Jesada Sivaraks, and Nattakit Suriyakrai
}

\begin{abstract}
The dynamic permittivity of microstrip structure deduced by adopting the Cole-Cole diagram results in a modified smith-chart representation (FDSC) that takes into the account the frequency-dependent influence of the fringing field and lossy characteristics of the line cohesively. This research illustrates microstrip patch antenna system for wireless communications applications that operates on $2.45 \mathrm{MHz}$ ISM band. The impedance matching is a part of the design process to maximize power in the antenna system. This model proposed in this research is compatible with computer aided design system (CAD) and hence, fast and easy for implementation.
\end{abstract}

Index Terms-Antenna design, computer aided design (CAD), frequency dependent smith chart (FDSC), impedance matching, microstrip.

\section{INTRODUCTION}

The adoption of frequency-dependent (lossy) Smith-chart representation is proved to be an effective method for rectangular microstrip antenna design [1]. The Industrial, Scientific and Medical (ISM) frequency bands governed by Federal Communications Commission (FCC) Part 15 specifications have seen dramatic growth in recent years, particularly for 2.4000 to $2.4835 \mathrm{GHz}$ (ISM-2400) band.

In this paper, the present effort addresses the design of an antenna system for wireless communication applications, which operates in the $2.45 \mathrm{GHz}$ (ISM) band. First, the design of the rectangular microstrip patch antenna is demonstrated by using the FDSC model in [2], [3] Then, the impedance matching methods for the antenna are indicated. Finally, the analysis and comparison of the FDSC design and the conventional model [4] are presented.

\section{Rectangular Microstrip PATCH ANTENNA DESIGN}

For the present design, the rectangular microstrip antenna has a substrate with dielectric constant $\left(\varepsilon_{r}\right)$ of 2.5 and the antenna is a direct-feed type. The size of the patch is $4.10 \mathrm{~cm}(w) \times 4.14 \mathrm{~cm}(l)(w=0.335 \lambda ; l=0.3382 \lambda$ at $f=2.45 \mathrm{GHz})$ and a thickness of $h=0.1524 \mathrm{~cm}$ ( $h=$ $0.0125 \lambda$ at $f=2.45 \mathrm{GHz})$. Fig. 1 shows the input impedances calculated as per the FDSC model [2], [3] and that by the Abboud's model [4] for the patch operating at $2.45 \mathrm{GHz}$. The design of the matching section for the antenna will be the next step and is discussed in the following sections.

Manuscript received October 30, 2013; revised January 6, 2014.

The authors are with the National Broadcasting and Telecommunications Commission (email: \{settapong.m, jesada.s, nattakit.s\}@nbtc.go.th).

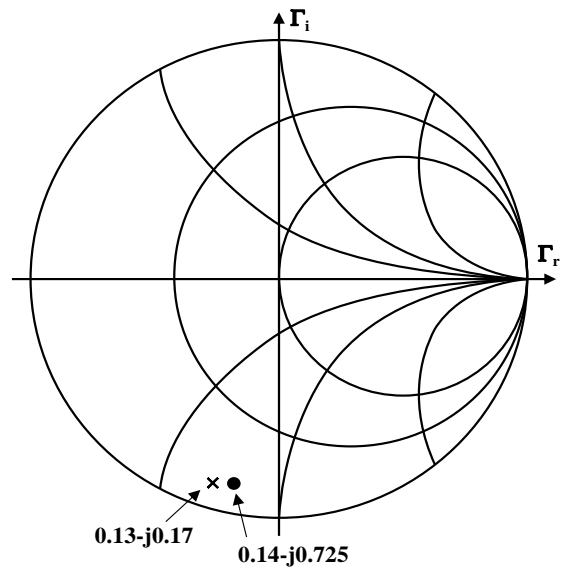

Fig. 1. The input impedance for a patch operating at $2.45 \mathrm{GHz} \bullet$ FDSC model $\times$ Calculate [4].

\section{NARROWBAND MATCHING}

The impedance matching is a part of the design process for a microwave component or system where maximum power transfer is crucial. Impedance matching is pertinent because:

- Greatest and most efficient level of power is delivered when the load is matched to the line.

- Impedance matching power distribution network particularly in antenna will reduce amplitude and phase errors.

The quarter-wave transformer is a simple structure compatible for matching real load impedance to a transmission line. An additional feature of the quarter-wave transformer is that it can be extended to multi-section designs for broader bandwidths.

As a first step, how the input impedance varies with frequency when a single quarter-wave section is terminated in a pure resistance is considered. A drawback of a single section quarter-wave transformer is that it can only match a real load impedance. Complex load impedance as illustrated in Fig. 1 can be altered to a real part by using an suitable length of transmission line between the load and the transformer as illustrated in Fig. 2. For the example under discussion, the line-length required to transform the complex impedance to the real values are $1.236 \mathrm{~cm}(0.101 \lambda$ at $f=2.45 \mathrm{GHz})$ and $1.102 \mathrm{~cm}(0.09 \lambda$ at $f=2.45 \mathrm{GHz})$ for the FDSC model and the Abboud's model, respectively.

The quarter-wave section required for matching should have characteristic impedance $R_{0}^{\prime}$ given by

$$
R_{0}^{\prime}=\sqrt{R_{R} R_{0}}
$$




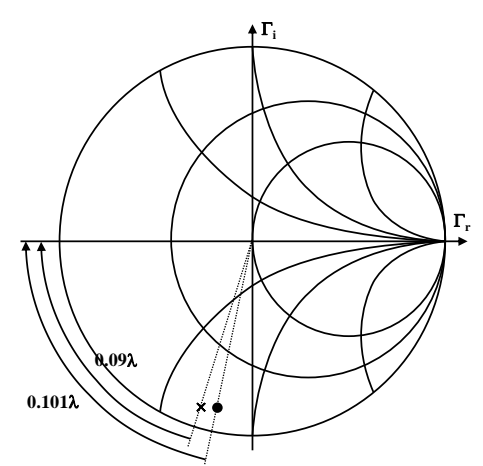

Fig. 2. Moving complex load impedance to a real impedance $\bullet F D S C$ model $\times$ Calculate [4]

The input impedance of the matched line, $Z_{\text {in }}$ as a function of frequency can be obtained by using a Smith-chart. Normalizing the all quantities with respect to $R_{0}^{\prime}$,

$$
\begin{gathered}
r_{r}^{\prime}=\frac{R_{R}}{R_{0}^{\prime}} \\
r_{0}^{\prime}=\frac{R_{0}}{R_{0}^{\prime}}
\end{gathered}
$$

For the design a lossless transformer section is assumed; hence the phase velocity is independent of frequency and $f \lambda=f_{0} \lambda_{0}$. Therefore, at any frequency $f$ the transformer length as a fraction of the wavelength is given by

$$
\frac{l}{\lambda}=\frac{l}{\lambda_{0}} \frac{f}{f_{0}}=0.25
$$

Eq. (3) is used to compute the electrical length of the transformer in Table I over the range $0.5 \leq f / f_{0} \leq 1.5$.

TABLE I: CALCULATION OF $Z_{\mathrm{IN}}$ FOR A QUARTER-WAVE TRANSFORMER (ABBOUD'S MODEL)

\begin{tabular}{|c|c|c|c|}
\multicolumn{4}{|c}{$f_{0}=2.45 \mathrm{GHz}, r^{\prime} r=0.36, Z_{\text {in }}=0.36 Z_{\text {in }}^{\prime}$} \\
\hline$f / f_{0}$ & $l / \lambda$ & $Z_{\text {in }}^{\prime}$ & $Z_{\text {in }}$ \\
\hline 1.5 & 0.375 & $0.65-\mathrm{j} 0.77$ & $0.23-\mathrm{j} 0.28$ \\
\hline 1.4 & 0.350 & $0.85-\mathrm{j} 0.95$ & $0.31-\mathrm{j} 0.34$ \\
\hline 1.3 & 0.325 & $1.19-\mathrm{j} 1.12$ & $0.43-\mathrm{j} 0.40$ \\
\hline 1.2 & 0.300 & $1.70-\mathrm{j} 1.18$ & $0.61-\mathrm{j} 0.42$ \\
\hline 1.1 & 0.275 & $2.50-\mathrm{j} 0.82$ & $0.90-\mathrm{j} 0.29$ \\
\hline 1.0 & 0.250 & 2.80 & 1.01 \\
\hline 0.9 & 0.225 & $2.50+\mathrm{j} 0.82$ & $0.90+\mathrm{j} 0.29$ \\
\hline 0.8 & 0.200 & $1.70+\mathrm{j} 1.18$ & $0.61+\mathrm{j} 0.42$ \\
\hline 0.7 & 0.175 & $1.19+\mathrm{j} 1.12$ & $0.43+\mathrm{j} 0.40$ \\
\hline 0.6 & 0.150 & $0.85+\mathrm{j} 0.95$ & $0.31+\mathrm{j} 0.34$ \\
\hline 0.5 & 0.125 & $0.65+\mathrm{j} 0.77$ & $0.23+\mathrm{j} 0.28$ \\
\hline
\end{tabular}

Since $R_{R}$ is independent of frequency, by using the Smith-chart (Fig. 3) at $r_{r}^{\prime}$, and rotate $1 / \lambda$ on the $S^{\prime}=r_{r}^{\prime}$, circle for each frequency to find the corresponding value of normalized input impedance $z^{\prime}{ }_{\text {in }}$. A typical rotation is shown in the Fig. 3 for $f / f_{0}=0.5, l / \lambda=0.125$.

The results are tabulated in Table I. By (2b) it may be seen that the match is perfect at $f / f_{0}$. The input impedance normalized with respect to $R_{0}$ is obtained by,

$$
z_{\text {in }}=\frac{Z_{\text {in }}}{R_{0}}=\frac{Z_{\text {in }}}{R_{0}^{\prime}} \frac{R_{0}^{\prime}}{R_{0}}=\frac{R_{0}^{\prime}}{R_{0}}
$$

Value of $z_{\text {in }}$ are shown in Table I and II for the FDSC model and that of the Abboud's model [4].
From Tables I-II and Fig. 3, Fig. 4, and Fig. 5, it illustrates that the maximum standing wave ratio is stipulated as 2 , the allowable bandwidth of the FDSC model shows a greater value than that of the Abboud's model [4], to an extent of about $11.40 \%$. A possible explanation is that $\Delta f / f$ (bandwidth) is directly proportional to the loss of the system [5]. Therefore, when the frequency-dependent characteristic impedance is taken into the calculation, it is reflected in an increase of bandwidth calculated (using FDSC model). The structure and dimension of the designed antenna is obtained in Fig. 6 and Table III.

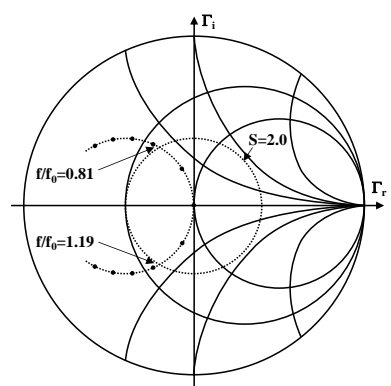

Fig. 3. Frequency response of a quarter-wave transformer for Abboud's model; $\Delta f / f$ (bandwidth $)=0.38$ or bandwidth $(\Delta f=0.931 \mathrm{GHz})$.

TABLE II: CALCULATION OF $Z_{\text {IN }}$ FOR A QUARTER-WAVE TRANSFORMER (FDSC MODEL)

\begin{tabular}{|c|c|c|c|c|}
\hline \multicolumn{5}{|c|}{$f_{0}=2.45 \mathrm{GHz}, r^{\prime} r=0.37, Z_{\text {in }}=0.37 Z_{\text {in }}^{\prime}$} \\
\hline$f / f_{0}$ & $\imath / \lambda$ & $Z_{\text {in }}^{\prime}$ & $Z_{\text {in }}$ & $\begin{array}{c}Z_{\text {in }} \\
\text { (FDS model) }\end{array}$ \\
\hline 1.5 & 0.375 & $0.66-\mathrm{j} 0.75$ & $0.24-\mathrm{j} 0.28$ & $0.23-\mathrm{j} 0.24$ \\
\hline 1.4 & 0.350 & $0.87-\mathrm{j} 0.93$ & $0.32-\mathrm{j} 0.34$ & $0.31-\mathrm{j} 0.24$ \\
\hline 1.3 & 0.325 & $1.19-\mathrm{j} 1.08$ & $0.44-\mathrm{j} 0.40$ & $0.43-\mathrm{j} 0.37$ \\
\hline 1.2 & 0.300 & $1.70-\mathrm{j} 1.11$ & $0.63-\mathrm{j} 0.41$ & $0.62-\mathrm{j} 0.38$ \\
\hline 1.1 & 0.275 & $2.35-\mathrm{j} 0.80$ & $0.87-\mathrm{j} 0.30$ & $0.85-\mathrm{j} 0.26$ \\
\hline 1.0 & 0.250 & 2.70 & 1.00 & 0.95 \\
\hline 0.9 & 0.225 & $2.35+\mathrm{j} 0.80$ & $0.87+\mathrm{j} 0.30$ & $0.85+\mathrm{j} 0.26$ \\
\hline 0.8 & 0.200 & $1.70+\mathrm{j} 1.11$ & $0.63+\mathrm{j} 0.41$ & $0.62+\mathrm{j} 0.38$ \\
\hline 0.7 & 0.175 & $1.19+\mathrm{j} 1.08$ & $0.44+\mathrm{j} 0.40$ & $0.43+\mathrm{j} 0.37$ \\
\hline 0.6 & 0.150 & $0.87+\mathrm{j} 0.93$ & $0.32+\mathrm{j} 0.34$ & $0.31+\mathrm{j} 0.31$ \\
\hline 0.5 & 0.125 & $0.66+\mathrm{j} 0.75$ & $0.24+\mathrm{j} 0.28$ & $0.23+\mathrm{j} 0.24$ \\
\hline
\end{tabular}

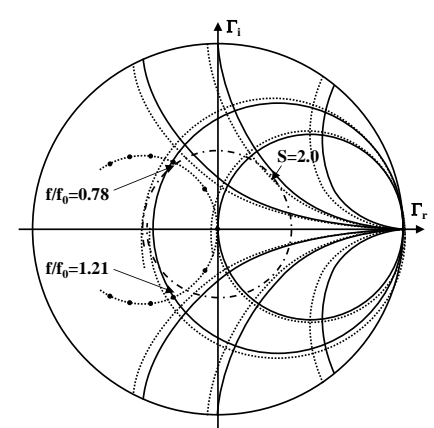

Fig. 4. Frequency response of a quarter-wave transformer for the FDSC model; $\Delta f / f$ (bandwidth $)=0.43$ or bandwidth $(\Delta f=1.051 \mathrm{GHz})$.

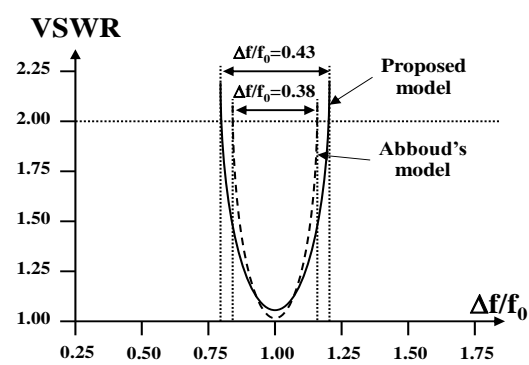

Fig. 5. Comparison bandwidth between Abboud's model and FDSC model with VSWR $\leq 2.0$. 


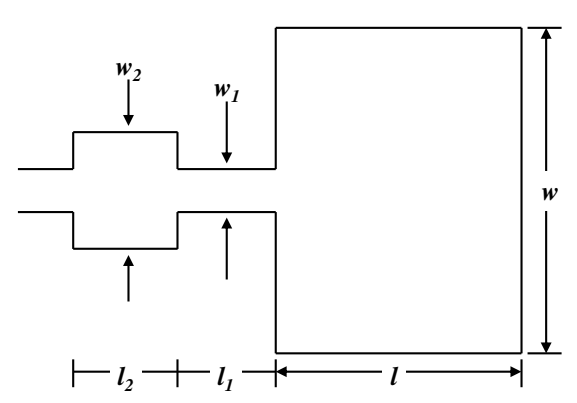

Fig. 6. Antenna structure and double-wave-transformer.

TABLE III: COMPARISON BETWEEN ABBOUD’S MODEL AND FDSC MODEL

\begin{tabular}{|c|c|c|c|}
\hline Model & $\begin{array}{c}\text { Abboud's } \\
\text { model }\end{array}$ & FDSC model & $\Delta(\%$ difference $)$ \\
\hline$w 1$ & $\begin{array}{c}0.435 \mathrm{~cm} \\
(0.0355 \lambda 0)\end{array}$ & $\begin{array}{c}0.435 \mathrm{~cm} \\
(0.0355 \lambda 0)\end{array}$ & 0 \\
\hline$w 2$ & $\begin{array}{c}1.650 \mathrm{~cm} \\
(0.1348 \lambda 0)\end{array}$ & $\begin{array}{c}1.579 \mathrm{~cm} \\
(0.1290 \lambda 0)\end{array}$ & 4.3 \\
\hline$\imath 1$ & $\begin{array}{l}1.102 \mathrm{~cm} \\
(0.0900 \lambda 0)\end{array}$ & $\begin{array}{c}1.236 \mathrm{~cm} \\
(0.1010 \lambda 0)\end{array}$ & 10.84 \\
\hline 12 & $\begin{array}{c}3.060 \mathrm{~cm} \\
(0.2500 \lambda 0)\end{array}$ & $\begin{array}{c}3.060 \mathrm{~cm} \\
(0.2500 \lambda 0)\end{array}$ & 0 \\
\hline $\begin{array}{c}\text { Bandwidth } \\
\text { (GHz) }\end{array}$ & 0.931 & 1.051 & 11.42 \\
\hline
\end{tabular}

\section{BROADBAND MATCHING}

As mentioned earlier, the broadband design can be achieved by using a set of cascaded quarter-wave transformer sections. Assuming that two or more quarter-wave sections are connected in cascade to transform $R_{R}$ to $R_{\text {in }}$, the problem is then to determine $R_{0}^{\prime}, R_{0}^{\prime \prime}, R_{0}^{\prime \prime \prime}$, namely, the characteristic impedances of these sections. A number of approaches have been identified in the frequency dependent smith chart (FDSC) literature to determine $R_{0}^{\prime}, R_{0}^{\prime \prime}, R_{0}^{\prime \prime \prime}$.For instance, Slater [6] has suggested the use of common logarithms of the impedance ratios at the junctions in the system with the coefficients of the binomial expansion $(a+b)^{n}$, as indicated below:

\begin{tabular}{|l|l|}
\hline No. of $\lambda / 4$ section, $n$ & Logarithm of impedance ratio \\
\hline 2 & 121 \\
\hline 3 & 1331 \\
\hline 4 & 14641 \\
\hline
\end{tabular}

For the present application, consider the design of a two-quarter-wave-section system. Reading from left to right-in the inset of Fig. 7, the impedance ratios at the junctions are $R_{R} / R_{0}^{\prime}, R_{0}^{\prime} / R_{0}^{\prime \prime}$, and $R_{0}^{\prime \prime} / R_{0}$. Since the number of sections, $n$, is equal to 2 ,

$$
\log \left(\frac{R_{0}^{\prime}}{R_{0}^{\prime \prime}}\right)=2 \log \left(\frac{R_{0}^{\prime \prime}}{R_{0}}\right)=2 \log \left(\frac{R_{R}}{R_{0}}\right)
$$

That is, from left to right, the logarithms of the impedance ratios follow the rule $12 \mathrm{I}$ in accordance with the above table. Then, taking antilogarithms,

$$
\frac{R_{0}^{\prime}}{R_{0}^{\prime \prime}}=\left(\frac{R_{0}^{\prime \prime}}{R_{0}}\right)^{2}=\left(\frac{R_{R}}{R_{0}^{\prime}}\right)^{2}
$$

Solving for $R_{0}^{\prime}$ and $R_{0}^{\prime \prime}$ in terms of $R_{0}$ and $R_{R}$

$$
\begin{gathered}
R_{0}^{\prime}=\frac{R_{0} R_{R}}{R_{0}^{\prime \prime}} \text { or } R_{0}^{\prime}=\sqrt[4]{R_{R}^{3} R_{0}} \\
R_{0}^{\prime \prime}=\frac{R_{0} R_{R}}{R_{0}^{\prime}}
\end{gathered}
$$

The impedance at the junction of the two quarter-wave sections is (Fig. 6)

$$
R_{0}^{\prime \prime}=\frac{R_{0} R_{R}}{R_{0}^{\prime}}
$$

This transformation will now be used to design a double-section system for an over-all transformation ratio of $R_{p}: R_{0}$.

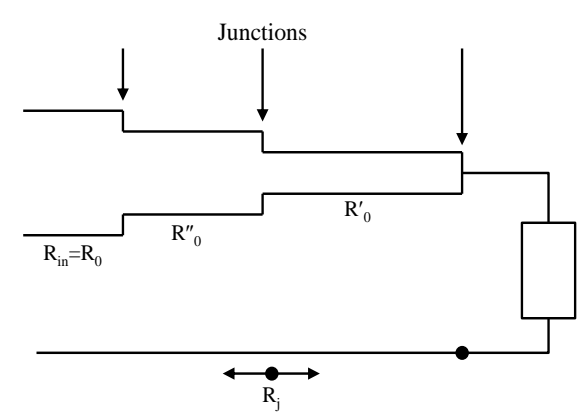

Fig. 7. Two cascaded quarter-wave transformers terminated in a constant resistive load

As a first step, consider the right-hand section, and normalized $R_{R}$ with respect to $R_{o}^{\prime}$ :

$$
r_{r}^{\prime}=\frac{R_{R}}{R_{0}^{\prime}}
$$

By (9) the normalized input impedance should be

$$
r_{j}^{\prime}=\frac{R_{R}}{R_{0}^{\prime}}
$$

Following the method of the last section, enter $r_{r}^{\prime}$ value on the Smith chart diagram, and rotate on a circle of constant $S^{\prime}$ the appropriate fraction of a wavelength at each frequency. The values of $z_{j}^{\prime}$ are tabulated in Table IV and Table V, and the corresponding locus is shown in the Fig. 8 and Fig. 9.

Now, $Z_{j}$ is the termination for the left-hand quarter-wave transformer in Fig. 7. To handle this section on the Smith-diagram, all quantities should be normalized with respect to $R_{0}^{\prime \prime}$. The double prime will indicate these quantities; thus,

$$
z_{j}^{\prime \prime}=\frac{z_{j}}{R_{0}^{\prime \prime}}=\frac{z_{j}}{R_{0}^{\prime}} \frac{R_{0}^{\prime}}{R_{0}^{\prime \prime}}=\frac{R_{0}^{\prime}}{R_{0}^{\prime \prime}} z_{j}^{\prime}
$$

Since $z_{j}^{\prime \prime}$ at each frequency and rotating toward the generator on a circle of constant $S^{\prime \prime}$ the appropriate distance indicated in the table. $Z_{\text {in }}$ is determined by,

$$
Z_{\text {in }}=\frac{Z_{\text {in }}}{R_{0}}=\frac{Z_{\text {in }}}{R_{0}^{\prime \prime}} \frac{R_{0}^{\prime \prime}}{R_{0}}=\frac{R_{0}^{\prime \prime}}{R_{0}} Z_{\text {in }}^{\prime \prime}
$$

The calculated results are shown in Tables IV-VI and Fig. 8, Fig. 9, and Fig. 10. The results indicate that, in the 
broadband matching, the bandwidth $(\Delta f / f=0.8)$ is greater than that of the narrowband matching $(\Delta f / f=0.43)$ or $46.25 \%$ difference as shown in Fig. 5 and Fig. 10. Further, it can be observed that the error between the FDSC model and the Abboud's model is $10 \%$ as shown in Table VI. The structure and dimension of the designed antenna is obtained in Fig. 11 and Table VI.

TABLE IV: CALCULATION OF $Z_{\text {IN }}$ FOR A QUARTER-WAVE TRANSFORMER (ABBOUD'S MODEL)

\begin{tabular}{|c|c|c|c|c|c|}
\hline \multicolumn{6}{|c|}{$f_{0}=2.45 \mathrm{GHz}, r^{\prime} r=0.6, r_{j}^{\prime}=1.67, r_{j}^{\prime \prime}=0.36 r^{\prime} j, Z_{\text {in }}=0.6 Z_{i n}^{\prime \prime}$} \\
\hline$f / f_{0}$ & $L / \lambda$ & $Z_{j}^{\prime}$ & $Z_{j}^{\prime \prime}$ & $Z_{\text {in }}^{\prime \prime}$ & $Z_{\text {in }}$ \\
\hline 1.5 & 0.375 & $\begin{array}{c}0.89-\mathrm{j} \\
0.46\end{array}$ & $\begin{array}{c}0.32-\mathrm{j} \\
0.17\end{array}$ & $\begin{array}{c}0.83-\mathrm{j} \\
1.07\end{array}$ & $\begin{array}{c}0.49-\mathrm{j} \\
0.64\end{array}$ \\
\hline 1.4 & 0.350 & $\begin{array}{c}1.04-\mathrm{j} \\
0.51\end{array}$ & $\begin{array}{c}0.37-\mathrm{j} \\
0.18\end{array}$ & $\begin{array}{c}1.30-\mathrm{j} \\
1.15\end{array}$ & $\begin{array}{c}0.78-\mathrm{j} \\
0.69\end{array}$ \\
\hline 1.3 & 0.325 & $\begin{array}{c}1.20-\mathrm{j} \\
0.50\end{array}$ & $\begin{array}{c}0.43-\mathrm{j} \\
0.18\end{array}$ & $\begin{array}{c}1.85-\mathrm{j} \\
0.85\end{array}$ & $\begin{array}{c}1.10-\mathrm{j} \\
0.51\end{array}$ \\
\hline 1.2 & 0.300 & $\begin{array}{c}1.41-\mathrm{j} \\
0.42\end{array}$ & $\begin{array}{c}0.51-\mathrm{j} \\
0.15\end{array}$ & $\begin{array}{c}1.93-\mathrm{j} \\
0.34\end{array}$ & $\begin{array}{c}1.16-\mathrm{j} \\
0.20\end{array}$ \\
\hline 1.1 & 0.275 & $\begin{array}{c}1.57-\mathrm{j} \\
0.25\end{array}$ & $\begin{array}{c}0.57-\mathrm{j} \\
0.09\end{array}$ & $\begin{array}{c}1.77-\mathrm{j} \\
0.04\end{array}$ & $\begin{array}{c}1.06-\mathrm{j} \\
0.02\end{array}$ \\
\hline 1.0 & 0.250 & 1.64 & 0.59 & 1.68 & 1.01 \\
\hline 0.9 & 0.225 & $\begin{array}{c}1.57+\mathrm{j} \\
0.25\end{array}$ & $\begin{array}{c}0.57+\mathrm{j} \\
0.09\end{array}$ & $\begin{array}{c}1.77+\mathrm{j} \\
0.04\end{array}$ & $\begin{array}{c}1.06+\mathrm{j} \\
0.02\end{array}$ \\
\hline 0.8 & 0.200 & $\begin{array}{c}1.41+\mathrm{j} \\
0.42\end{array}$ & $\begin{array}{c}0.51+\mathrm{j} \\
0.15\end{array}$ & $\begin{array}{c}1.93+\mathrm{j} \\
0.34\end{array}$ & $\begin{array}{c}1.16+\mathrm{j} \\
0.20\end{array}$ \\
\hline 0.7 & 0.175 & $\begin{array}{c}1.20+\mathrm{j} \\
0.50\end{array}$ & $\begin{array}{c}0.43+\mathrm{j} \\
0.18\end{array}$ & $\begin{array}{c}1.85+\mathrm{j} \\
0.85\end{array}$ & $\begin{array}{c}1.10+\mathrm{j} \\
0.51\end{array}$ \\
\hline 0.6 & 0.150 & $\begin{array}{c}1.04+\mathrm{j} \\
0.51\end{array}$ & $\begin{array}{c}0.37+\mathrm{j} \\
0.18\end{array}$ & $\begin{array}{c}1.30+\mathrm{j} \\
1.15\end{array}$ & $\begin{array}{c}0.78+\mathrm{j} \\
0.69\end{array}$ \\
\hline 0.5 & 0.125 & $\begin{array}{c}0.89+\mathrm{j} \\
0.46\end{array}$ & $\begin{array}{c}0.32+\mathrm{j} \\
0.17\end{array}$ & $\begin{array}{c}0.83+\mathrm{j} \\
1.07\end{array}$ & $\begin{array}{c}0.49+\mathrm{j} \\
0.64\end{array}$ \\
\hline
\end{tabular}

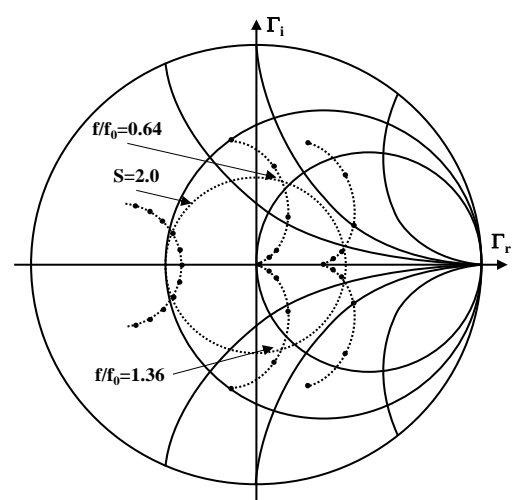

Fig. 8. Frequency response of quarter-wave transformer for Abboud's model; $\Delta f / f$ (bandwidth $)=0.72$ or bandwidth $(\Delta f=1.764 \mathrm{GHz})$.

TABLE V: CALCULATION OF $Z_{\text {IN }}$ FOR A QUARTER-WAVE TRANSFORMER (FDSC MODEL)

$f_{0}=2.45 \mathrm{GHz}, r^{\prime} r=0.61, r_{j}^{\prime}=1.64, r_{j}^{\prime \prime}=0.37 r_{j}^{\prime}$

\begin{tabular}{|c|c|c|c|c|c|}
\hline$f / f_{0}$ & $L / \lambda$ & $Z_{j}^{\prime}$ & $Z_{j}^{\prime \prime}$ & $Z_{\text {in }}^{\prime \prime}$ & $\begin{array}{c}Z_{\text {in }} \\
\text { (FDSC } \\
\text { model) }\end{array}$ \\
\hline 1.5 & 0.375 & $\begin{array}{c}0.88-\mathrm{j} \\
0.46\end{array}$ & $\begin{array}{c}0.33-\mathrm{j} \\
0.17\end{array}$ & $\begin{array}{c}0.91-\mathrm{j} \\
1.16\end{array}$ & $\begin{array}{c}0.54+\mathrm{j} \\
0.66\end{array}$ \\
\hline 1.4 & 0.350 & $\begin{array}{c}1.03-\mathrm{j} \\
0.51\end{array}$ & $\begin{array}{c}0.38-\mathrm{j} \\
0.19\end{array}$ & $\begin{array}{c}1.47-\mathrm{j} \\
1.15\end{array}$ & $\begin{array}{c}0.88+\mathrm{j} \\
0.67\end{array}$ \\
\hline 1.3 & 0.325 & $\begin{array}{c}1.20-\mathrm{j} \\
0.51\end{array}$ & $\begin{array}{c}0.44-\mathrm{j} \\
0.19\end{array}$ & $\begin{array}{c}1.94-\mathrm{j} \\
0.70\end{array}$ & $\begin{array}{c}1.14+\mathrm{j} \\
0.39\end{array}$ \\
\hline 1.2 & 0.300 & $\begin{array}{c}1.42-\mathrm{j} \\
0.44\end{array}$ & $\begin{array}{c}0.53-\mathrm{j} \\
0.16\end{array}$ & $\begin{array}{c}1.90-\mathrm{j} \\
0.20\end{array}$ & $\begin{array}{c}1.12+\mathrm{j} \\
0.12\end{array}$ \\
\hline 1.1 & 0.275 & $\begin{array}{c}1.60-\mathrm{j} \\
0.25\end{array}$ & $\begin{array}{c}0.59-\mathrm{j} \\
0.09\end{array}$ & $\begin{array}{c}1.70-\mathrm{j} \\
0.02\end{array}$ & $\begin{array}{c}1.02+\mathrm{j} \\
0.02\end{array}$ \\
\hline 1.0 & 0.250 & 1.68 & 0.62 & 1.64 & 0.95 \\
\hline 0.9 & 0.225 & $\begin{array}{c}1.60+\mathrm{j} \\
0.25\end{array}$ & $\begin{array}{c}0.59+\mathrm{j} \\
0.09\end{array}$ & $\begin{array}{c}1.70+\mathrm{j} \\
0.02\end{array}$ & $\begin{array}{c}1.00+\mathrm{j} \\
0.01\end{array}$ \\
\hline 0.8 & 0.200 & $\begin{array}{c}1.42+\mathrm{j} \\
0.44\end{array}$ & $\begin{array}{c}0.53+\mathrm{j} \\
0.16\end{array}$ & $\begin{array}{c}1.90+\mathrm{j} \\
0.20\end{array}$ & $\begin{array}{c}1.10+\mathrm{j} \\
0.10\end{array}$ \\
\hline 0.7 & 0.175 & $\begin{array}{c}1.20+\mathrm{j} \\
0.51\end{array}$ & $\begin{array}{c}0.44+\mathrm{j} \\
0.19\end{array}$ & $\begin{array}{c}1.94+\mathrm{j} \\
0.70\end{array}$ & $\begin{array}{c}1.15+\mathrm{j} \\
0.37\end{array}$ \\
\hline 0.6 & 0.150 & $\begin{array}{c}1.03+\mathrm{j} \\
0.51\end{array}$ & $\begin{array}{c}0.38+\mathrm{j} \\
0.19\end{array}$ & $\begin{array}{c}1.47+\mathrm{j} \\
1.15\end{array}$ & $\begin{array}{c}0.87+\mathrm{j} \\
0.66\end{array}$ \\
\hline 0.5 & 0.125 & $\begin{array}{c}0.88+\mathrm{j} \\
0.46\end{array}$ & $\begin{array}{c}0.33+\mathrm{j} \\
0.17\end{array}$ & $\begin{array}{c}0.91+\mathrm{j} \\
1.16\end{array}$ & $\begin{array}{c}0.54+\mathrm{j} \\
0.68\end{array}$ \\
\hline
\end{tabular}

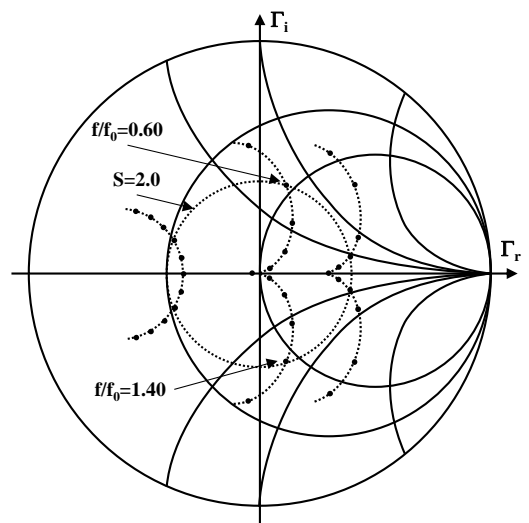

Fig. 9. Frequency response of a quarter-wave transformer for the FDSC model ; $\Delta f / f$ (bandwidth $)=0.80$ or bandwidth $(\Delta f=1.96 \mathrm{GHz})$.

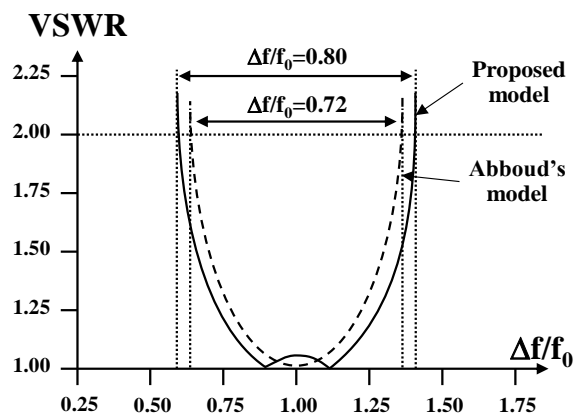

Fig. 10. Comparison bandwidth between Abboud's model and FDSC model with VSWR $\leq 2.0$.

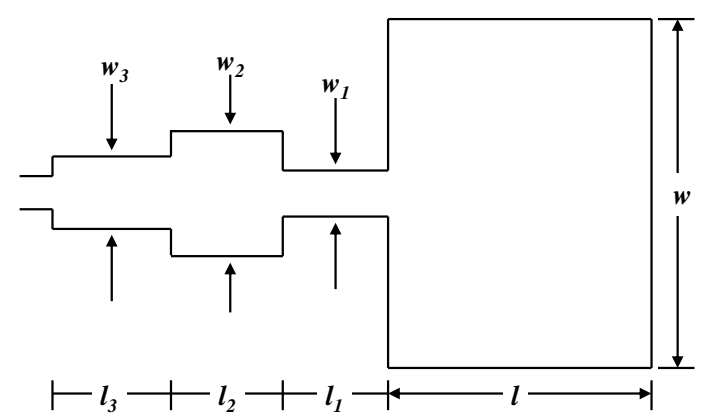

Fig. 11. Antenna structure and double-wave-transformer.

TABLE VI: COMPARISON BETWEEN ABBOUD's MODEL AND FDSC MODEL

\begin{tabular}{|c|c|c|c|}
\hline \multicolumn{4}{|c|}{$\left(f_{0}=2.45 \mathrm{GHz}\right)$} \\
\hline Model & $\begin{array}{c}\text { Abboud's } \\
\text { model }\end{array}$ & $\begin{array}{l}\text { FDSC } \\
\text { model }\end{array}$ & $\Delta(\%$ difference $)$ \\
\hline$w 1$ & $\begin{array}{c}0.435 \mathrm{~cm} \\
(0.0355 \lambda 0)\end{array}$ & $\begin{array}{c}0.435 \mathrm{~cm} \\
(0.0355 \lambda 0)\end{array}$ & 0 \\
\hline$w 2$ & $\begin{array}{c}2.950 \mathrm{~cm} \\
(0.2410 \lambda 0)\end{array}$ & $\begin{array}{c}2.785 \mathrm{~cm} \\
(0.2275 \lambda 0) \\
\end{array}$ & 5.59 \\
\hline$w 3$ & $\begin{array}{c}0.880 \mathrm{~cm} \\
(0.0719 \lambda 0)\end{array}$ & $\begin{array}{c}0.884 \mathrm{~cm} \\
(0.0722 \lambda 0)\end{array}$ & 0.45 \\
\hline$\imath 1$ & $\begin{array}{l}1.102 \mathrm{~cm} \\
(0.0900 \lambda 0)\end{array}$ & $\begin{array}{c}1.236 \mathrm{~cm} \\
(0.1010 \lambda 0)\end{array}$ & 10.84 \\
\hline 12 & $\begin{array}{c}3.060 \mathrm{~cm} \\
(0.2500 \lambda 0)\end{array}$ & $\begin{array}{c}3.060 \mathrm{~cm} \\
(0.2500 \lambda 0)\end{array}$ & 0 \\
\hline 13 & $\begin{array}{c}3.060 \mathrm{~cm} \\
(0.2500 \lambda 0)\end{array}$ & $\begin{array}{c}3.060 \mathrm{~cm} \\
(0.2500 \lambda 0)\end{array}$ & 0 \\
\hline $\begin{array}{c}\text { Bandwidth } \\
\text { (GHz) }\end{array}$ & 1.764 & 1.960 & 10.00 \\
\hline
\end{tabular}

\section{CONCLUding REMARKS}

The use of modified smith-chart is proved to be an efficient method in representing the frequency characteristics of the microstrip line. This study further demonstrates the feasibility of a cohesive presentation of the dispersion (lossy 
and lossless) characteristics of a microstrip line via impedance matching. As indicated in this research, impedance matching in design process for the antenna allows efficient and greatest power to be delivered when the load is matched to the line. Further, impedance matching also reduces the amplitude and phase errors. Therefore, in this research it was concluded that in broadband matching, in adopting the FSDC representation in this case, error has been reduced by a significant level increasing the accuracy of the model. As a result, this research illustrates an efficient design of CAD compatible microstrip patch antenna system for wireless communications on $2.45 \mathrm{MHz}$ ISM band.

\section{REFERENCES}

[1] S. Malisuwan and J. Sivaraks, "Design of microstrip antenna for WPAN applications by applying modified smith-chart representation," ICCSS, International Journal of Modeling and Optimization, vol. 3, pp. 381-385, 2013

[2] J. J. Wang, Y. P. Zhang, K. M. Chua, and A. C. W. Lu, "Circuit model of microstrip patch antenna on ceramic land grid array package for antenna-chip co design of highly integrated RF transceivers," IEEE Tran. on Antennas and Propagation, vol. 53, no. 12, Dec. 2005.

[3] S. Malisuwan, P. Akkaraekthalin, K. Rosesukon, S. Huvanandana, and K. Nestsawang, "Co-Existence of cellular communication systems: Impact of WCDMA mobile to GSM1900 mobile interference," in Proc. International Symposium on Communications and Information Technologies (ISCIT2003), Thailand, 2003

[4] F. Abboud, J. P. Daminano, and A. Papiernik, "Simple model for the input impedance of coax-fed rectangular microstrip patch antenna for CAD", in IEE Proc. H, Microwaves, Antenna and Progag., vol. 135, 1988, pp. 323-326.

[5] S. Drabowitch, A. Papiernik, H. Griffiths, and J. Encinas, "Printed antenna," Modern Antennas, Chapman and Hall, Cambridge, 1998. ch. 6.

[6] J. C. Slater, Microwave Transmission, New York: MC Graw-Hill, 1942.

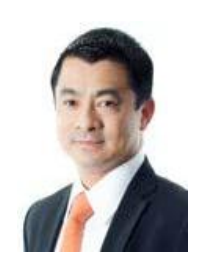

Settapong Malisuwan was born on March 24, 1966 in Bangkok, Thailand. He received his $\mathrm{PhD}$ in electrical engineering (telecommunications), specializing in mobile communication systems from Florida Atlantic University (State University System of Florida), Boca Raton in 2000. $\mathrm{He}$ received an MSc in electrical engineering in mobile communications system, from George Washington University in 1996, an MSc in electrical engineering in telecommunication engineering from Georgia Institute of Technology in 1992 and a BSc in electrical engineering from the Chulachomklao Royal Military Academy, Nakhon-Nayok, Thailand in 1990. He served in the Royal Thai Armed Forces for more than 25 years and is currently the Vice Chairman of National Broadcasting and Telecommunications, Bangkok, Thailand. His research interests are in efficient spectrum management and Telecommunications policy and management in Thailand.

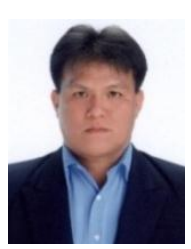

Jesada Sivaraks was born on May 12, 1970 in Bangkok, Thailand. He received his MSEE degree from Oklahoma State University in 1996 and BEng from King Mongkut"s Institute of Technology, Thailand. He completed his $\mathrm{PhD}$ in electrical engineering at Florida Atlantic University, Boca Raton, FL in 2001. Since 2011, he has been working in National Broadcasting and Telecommunications Commission as the secretary to the vice chairman. His $\mathrm{PhD}$ work is on the system aspects of Bluetooth, WLAN and Mobile IP/CDPD. His current research interests are in telecommunication planning and related system analysis and efficient spectrum management. He is a member of Tau Beta Pi, Florida Epsilon and was an Honorary Advisory's Chairman of Science \& Technology committee of Parliament in 2009.

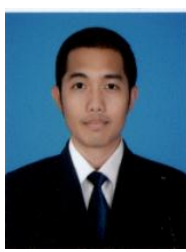

Nattakit Suriyakrai was born in Khonkhaen, Thailand on March 22, 1987. He received his bachelor of liberal arts in Japanese language from Thammasat University in 2010. He has been working as an assistant to vice chairman in national broadcasting and telecommunications, Bangkok, Thailand since November 2012. His research interests are in technology management and spectrum management. 